\title{
THE INTERRELATIONS OF WORLD ORGANIZATION AND SOCIETY
}

\author{
HAROLD D. LASSWELL†
}

THE nature and timing of world organization depend upon the global correlation of power with other elements in society. ${ }^{1}$ If the rate of attempted organization outruns the growth of strong sustaining elements in world society, collapse will surely follow; and collapse will probably come after the political élite, ${ }^{2}$ fearful of secession and revolution, creates a state which is not only a world garrison state, dominated by the military, but a world prison state dominated by the police. If, on the contrary, world organization lags behind the level which is capable of being attained by political skill at any particular time, humanity will remain under the shadow of atomic disaster. ${ }^{3}$

† Professor of Law, Yale School of Law; recently director of War Communications Research in Washington, D. C.; advisory editor of Ethics and associate editor of the Public Opinion Quarterly; author of various publications, including Propaganda Technique in the World War (1927); World Politics and Personal Insecurity (1935).

1. That political institutions in any community are affected by, and in turn act upon, all other institutions is well established. An institution is a pattern of practices by which values are shaped and distributed. A practice includes operations (like voting) and perspectives typically related to each operation (such as the doctrines, slogans, key symbols, and volitions connected with voting). Values are basic categories of desired events, like power, wealth and respect. On the interrelations of institutions, see for example: TimaShefF, An Introduction to the Sociology of Law (1939); Ehrlich, Fundamental Principles of the Sociology of Law (1936); Robson, Civilisation and the Growth of Law (1935); Commons, Legal Foundations of Capitalism (1924); Rusche and Kirchheimer, Punishment and Social Structure (1939); Ranulf, The Jealousy of the Gods and the Criminal Law at Athens (1934); Rougier, Les Mystiques PolitiQues Contemporaines et LeUrs InCidences Internationales (1935); Merriam, Systematic Politics (1945); Maciver, The Modern State (1926); Macleod, The Origin and History of Politics (1931); Llewellyn and Hoebel, The Cheyenne Way: Conflict and Case Law in Primitive Jurisprudence (1941).

2. Saint-Simon and other moderns have made descriptive use of the élite concept, meaning the parts of the social structure from which decision makers are drawn. See Mosca, The Ruling Class (1939); Pareto, The Mind and Society (1935); Weber, WirTsCHAFT UND GESEllschaft (1925).

3. On the military-police potentialities of modern times, see Lasswell, The Garrison State (1941) 46 AM. J. Soc. 455. Strictly speaking world organization is part of world society, and interacts continually with all institutions throughout the globe. In order to avoid the rather clumsy expression "and other institutions of society," the present article speaks of "world organization" and "society." It should also be noted that the term "world organization" is usually treated as synonymous with expressions like "world state," "world sovereign," "world body politic," "world government." We imply global control as well as authority, that is, a high level of effective as well as formal power. From a scientific point of view the problem is to formulate the conditions under which an inclusive pattern of authority and control can be achieved, and under which it breaks down. Let it be noted, further, that the term "world society" is usually taken to mean "all cultures on the globe," and is not restricted to an hypothetical pattern of one dominant (or even all-embracing) culture. 
If humanity is to reach beyond the insecurities of the present to a more abundant, humane and sanguine future, policies must mediate between reality and aspiration. If the goal is the reduction of human destructiveness and the maximizing of values such as safety, prosperity and democracy, it is necessary to take fully into account the trends, however grim, of global politics and society. ${ }^{4}$ In the present discussion we are concerned with two often facilitating, often interfering trends, one conditioned by factors leading toward a bipolar structure of world politics, the other by factors making toward a homogeneous world culture combining science and democracy.

\section{The Bipolar Trend in World Politics}

Two giant powers, the USA and the USSR, tend to confront one another on every significant issue in world affairs. Thus a bipolar system of world politics is taking the place of a pattern in which a few powers of approximately equal strength predominate (polypolarity). ${ }^{5}$

The form of politics is altered, though the basic process is intact. Whether domestic or international, politics is a perpetual balancing of power, conducted according to prevailing expectations about how decisions are made and put into effect. In the arena of international affairs choice presupposes violence in the sense that whether anyone wants it or not, he must at least admit the likelihood of future wars and seditions. In the arena of internal politics the expectation that violence will be resorted to in making decisions recedes into the background, and the assumption prevails that differences will be settled by ballot.

In the international arena the powers continually group and regroup in potentially hostile combinations. When four, five or more major powers predominate, every power can ally itself with every other. Under a bipolar system, on the contrary, this is out of the question, although intermediate powers continue to gravitate from one sphere into the other.

\section{A. The Alleged Transitional Character of Bipolar Systems}

For our purposes it is important to determine whether a two-power system is a "transition" toward "inevitable" unipolarity (by conquest or consent). Unfortunately exact historical parallels are missing.

Although the globe has never presented the tragic spectacle with which we are today obsessed, past circumstances afford instructive,

4. Concerning the goal values of democracy, see Lasswell and McDougal, Legal Education and Public Policy: Professional Training in the Public Interest (1943) 52 Yale L. J. 203.

5. On tripolarity in recent world politics, see Fox, The SUPER-Powers (1944); on bipolarity, Lasswell, World Politics Faces Economics (1945). 
if partial, parallels. Large areas have in the past been cut off from significant contact with other regions, and these highly independent arenas have exhibited every conceivable pattern of power (unipolar, bipolar, polypolar, multipolar).

In some cases a bipolar system has been superseded by a "universal" state or an "imperium." A universal state includes in one body politic all peoples who are in significant contact with one another. Examples are the Ts'in and Han Empire (221 B.C. to A.D. 172) in China, and in the New World the First Empire of the Mayas (about A.D. 300 to 690). In these cases it is most exact to speak of an "imperium," meaning a state which proclaims general or even universal authority and exercises overwhelming supremacy throughout the "known world." (Order may be chronically disturbed at remote boundaries inhabited by an ambiguous fringe of tribes.)

The record also reveals that bipolar systems do not invariably become unipolar. The two-state pattern has often broken into polypolar or multipolar forms. In fourth, fifth and sixth century China (A.D.), power was divided between the Southern and Northern Dynasties, and during part of the time the control exercised by the two dynasties was so feeble that the actual picture was multipolar. When the Roman Empire broke up, parallel developments occurred, and the division into East and West was ultimately followed by extensive fragmentation.

If a bipolar system is "inherently" unstable, it should pass away more quickly than other patterns. Although no generally accepted scholarly work satisfactorily classifies the patterns of power according to the number of years they have lasted in history, available evidence is enough to cast doubt upon the vulnerability of the two-state system. Unquestionably there has been a tendency to obscure the issue by exaggerating the permanence of one-state systems and to underplay bipolar structures. Arnold Toynbee, for instance, lists approximately twenty-three "universal states" which he alleges tend to endure four centuries each. ${ }^{6}$ Of the twenty-three, however, four are recorded as having lasted between two and three centuries ${ }^{7}$ and eight for shorter periods. ${ }^{8}$ Of the eleven "four century" examples, four and possibly more cases are not relevant to our present inquiry (they are not in-

6. The data are assembled in Table I of 6 ToynbeE, A Study of History (1939).

7. Hideyoshi's dictatorship and the Tokugawa Shogunate (1597-1868), Achaemenian Empire (c. 525-332 B.C.), the Manchu Empire (1644-1853), the Spanish Viceroyalty of New Spain (1521-1821).

8. The Neo-Babylonian Empire (610-539 B.C.), the Mughal Rāj (c. 1572-1707), the Guptan Empire (390-c. 475), the Mauryan Empire (1797-1814), the British Rāj (1818-), the Napoleonic Empire (1797-1814), the Incaic Empire (c. 1430-1533), the Mongol Empire (1280-1351). 
stances of unipolarity).$^{9}$ Of the seven (or fewer) remaining states, the four century period cannot be accepted since generations are counted in which central supremacy was nearly zero. ${ }^{10}$ Non-unipolar periods are lumped into "Times of Trouble," and dates are not assigned to the bipolar or other patterns that prevailed at such times.

The most likely conclusion touching upon the alleged instability of "bipolar" systems is that, like all systems of power in world politics, bipolarity is unstable. The relative degree of stability cannot be conclusively determined in relation to unipolar systems. (But it is highly probable that polypolar or multipolar systems have prevailed longer than bi- or uni-polarity in the political arenas of history.)

After all, one may ask, what is to be learned by counting up the dates on the tombstones of defunct patterns of world politics? No doubt the exercise enables us to dismiss glib remarks about "inevitability" or "instability," though in weighing future developments, the salient question is what factors sustain each system. Do the facts of comparative history make it possible to isolate the constellation of factors upon which each form of polarity depends?

\section{B. The Relation of Political Polarities to Society as a Whole}

The patterns of political polarity can for convenience be divided in two, according to the prevailing number of participants. When many small powers of about equal strength occupy an entire political arena, we speak of multipolarity. All the patterns that reduce the number of powers on a level of approximately equal strength can be called minimal power patterns (minimipolar patterns, for short). The minimipolar systems range all the way from one universal state or imperium to two giant powers, three super-powers, or a few great powers.

A clue to the nature of the interdependence between the pattern of power in world politics and the structure of society is given by the history of Europe. After the dissolution of the Roman Empire, a multipolar system prevailed most of the time, and this gave way to the modern "national" state system (polypolarity) only after the rise of a few great centers of trade and thought. The new sub-centers shared a homogeneous culture of greater technological productivity than before.

9. The Ottoman Empire (1372-1768), the Muscovite Empire (1478-1881), the Danubian Hapsburg Monarchy (1526-1918), the Arab Caliphate (640-969). Toynbee's "universal state" is defined to include all who have a common civilization, rather than those who are in significant contact with one another.

10. For instance, the troubles of third century Rome are severely minimized when Roman unity is alleged to continue without interruption. In some cases Toynbee gives weight (though on what basis is difficult to judge) to the facts of control as distinguished from nominal authority. Thus he dates the end of the Manchu Empire in China 1853, when Nanking was captured by the T'aip'ing insurgents, rather than 1912 when the dynasty was overthrown. 
The spread of such an advanced culture ("advanced" be it noted in the defined sense of productivity) ${ }^{11}$ carries as a corollary the widening of the gap between those who quickly acquire the new pattern and those who fail to do so. Hence a trend toward the sharing of a technically advanced culture, when accompanied by resistances, is accompanied by certain trends toward cultural disparity.

Our available knowledge of political and cultural history appears to support the following proposition: Polarities of power are interdependent with patterns of cultural homogeneity and disparity.

What is implied in relation to polypolarity is that the growth of a limited number of dominant centers participating in an advanced culture favors the growth of a polypolar system of power. This is the general picture, referred to above, presented by the Europe in which "national" states became powerful. ${ }^{12}$

Political bipolarity depends principally upon a bipolar pattern among the bearers of advanced culture. In the history of China, to recur to an example, a northern center of economic strength and cultural prestige has repeatedly stood over against a southern center, and political separatism has been nourished as a result. ${ }^{13}$ Similarly Upper and Lower Egypt were set off from one another at various times. ${ }^{14}$ Perhaps the most convincing indication of how bipolarity of power and of society are connected is the lack of political, economic and cognate forms of association between Russia and the surrounding world (despite the sharing of the modern technoscientific mode of production.) ${ }^{15}$

The relation between unipolar power and the common possession of a technically advanced culture is supported by much evidence. Toynbee, for instance, treats of history as a series of cultural wholes called civilizations, each of which becomes organized as a universal state when its distinctive features permeate a vast area. ${ }^{16}$ (Thus a high level of homogeneity with respect to an advanced culture paves the way for political unity, unless factors making for bipolarity inter-

11. It is important that descriptive rather than preferential categories be used in classifying cultures. On the basic issues, see Malinowski, A Scientific Theory of Culture and Other Essays (1944); Kroeber, Configurations of Culture Growth (1944).

12. Especially useful is Kulischer, Allgemeine Wirtschaftsgeschichte des Mittelalters UND DeR Neuzeit (1928-1929); also Heaton, Economic History of Europe (1936).

13. A convenient summary is Latourette, The Chinese: their History and CulTURE (1934).

14. Breasted, A History of Egypt (1912).

15. Russian development is given sympathetic treatment in Schuman, Soviet Politics at Home and Abroad (1946). Compare: Laserson, Russia and the Western WORLD (1945).

16. Wissler, MaN and Culture (1923) put forward the hypothesis that political authority tends to follow the zone of diffusion of material culture. 
fere.) Once attained, a unipolar system appears in many cases to reenforce the factors making for homogeneous culture.

But disparities of culture can aid in thwarting the success of onestate systems, as when an empire expands beyond its homogeneous base and is unable to bring about a sufficient degree of homogeneity in the new area to endure. However, disparate elements do not always struggle successfully against an empire; on the contrary, they may be made relatively permanent by being excluded from a full share in the advanced culture (possibly being transformed into castes or dependent peoples). ${ }^{17}$

The application of the foregoing analysis to the emerging picture of world affairs can be summarized as follows:

1. To the extent that a common and technically advanced civilization girdles the globe, conditions favorable to a united world prevail, unless the bearers of the common civilization become segregated around two territorial poles of economic and general cultural strength.

2. The continued existence of "primitive" peoples of disparate (technically backward) culture does not impede the possible formation of a world state by conquest.

3: A unipolar world, once achieved, will not necessarily endure, unless many sub-centers of homogeneous culture are rather evenly distributed over the globe.

4. A unipolar world does not necessarily involve the sharing of an advanced civilization; on the contrary, many groups may be permanently relegated into castes and dependent peoples.

The non-quantitative character of these generalizations renders them difficult of successful application to the developing world situation. We cannot specify, for instance, how much bipolarity of culture is necessary to sustain bipolarity of power, or how much homogeneity (or disparity) is essential to a unipolar system.

\section{The Nuclear Energy Crisis}

In estimating the future of bipolar patterns of power and society, and in outlining choices open to policymakers, it is imperative to evaluate the significance of recent advances in the release of nuclear energy (soon to be joined perhaps by spectacular developments in the field of cosmic radiation). It is generally agreed that in a few years the Soviet Union will have the "secret" of the bomb and that Russia may indeed improve upon the devices now in use. ${ }^{18}$ Further, it is

17. Information on slavery and castes is available in such a compendium as SUMNER, Keller, and Davie, The Science of Society (1927).

18. A convenient source of authoritative information is the Bulletin of THE ATOMIC Scientists (of Chicago) (1945). See also, A Report on the International Control of Atomic Energy, Dep't of State Publication No. 2498 (1946); Brodie (ed.), The Absolute Weapon: Atomic Power and World Order (1946). 
obvious that some anti-Russian elements desire to provoke a preventive war against the Soviet Union before the USSR achieves weapon parity. At the same time, there are tremendous official and popular pressures to set up adequate arrangements for the control of fissionable material. Three contingencies, therefore, must be inquired into:

C.1 Assuming that the USA and the USSR possess weapon parity, though no adequate international control is set up, what pattern of power and society is likely to emerge?

C.2 During the period of USA superiority in weapons, are there conditions under which the USA will undertake to organize the world by conquest, and with what results?

C.3 If a world atomic energy authority is established, will the world state follow immediately?

\section{C.1 Weapon Parity (without agreement)}

The first contingency would occur if war is avoided during the period of American weapon superiority, and if no international control system is organized. It is not difficult to foresee the immediate effect of weapon parity upon power and society: rigorous bipolarity would prevail. Eyeing one another for evidence of hostile activity, contact between the Russian and American zones would be kept at a minimum. Anyone permitted to cross the borders would be looked upon as a probable spy and put under constant surveillance. Trade and investment would be held down. Diplomatic relations would be tentative, suspicion-ridden, and meagre. Free communication:would be blacked out.

The most extensive transformation would take place in the area controlled by the USA. Recognizing the peril of "split-second" attack, civilian officials would become progressively more dependent upon military authorities. ${ }^{19}$ The Congress would multiply secret committee hearings, acquiesce in receiving less and less specific information about how the military proposes to spend appropriations, or how appropriations were spent during the last budgetary period. Fearing the communication of secrets to the enemy, freedom of scientific publication would disappear, and advanced teaching would be available only to students thoroughly "checked" for loyalty. All scientists, teachers, and students would be under unremitting scrutiny by military and police intelligence services. In this apprehensive atmosphere full and frank criticism of constituted authority would be stifled. Personal denunciations, often based upon personal spite, would add a relatively new note to American life.

American industry would become even more dependent upon mili-

19. In Baruch's telling phrase to the UN: "The bomb does not wait upon debate. To delay may be to die." N. Y. Times, June 15, 1946, p. 4, col. 5. 
tary approval for contracts, permission to use secret machines and processes, and access to raw material. Owners, executives and workers would be subject to security check by military and police authorities. Strikes and other suspensions of production would be interpreted as threats to national security.

Mass unemployment would not be permitted to continue for any considerable time, since production losses and social unrest would undermine the ability of the nation to repel attack. The government would resort to whatever measures were deemed necessary to maintain high levels of employment (relying at first upon the awarding of contracts and the advancing of credit). ${ }^{20}$ Every public and publicly supported private project would be coordinated with the advice (and eventually with the consent) of the military.

In this way the "painless" extinction of free private enterprise would be brought about since the continuation of each business would depend upon the good will of governmental (military) officials. This would go along with the "painless" extinction of freedom of education, research, news and comment, public discussion and agitation. The government (increasingly controlled by military considerations and military officials) would be the great news and knowledge source, and security regulations would guard and guide the dissemination of statements.

The most enlightened industrial and political-military executives, aware of the danger to national morale attending such profound transformations in American life and the danger of subversion, would urge the application of modern scientific knowledge of human relations ${ }^{21}$ to the task of easing the conversion of America into a garrison state. Enlightened leaders would insist upon the continuous clarification of each group about its place in the picture. Enlightened executives would insist upon as much active participation as possible, seeking to devise substitutes for the traditional channel of public debate. (Even if largescale meetings were eventually prohibited, everyone might belong to a council in his residential block, office, shop, factory, or other work place. Membership in such a council could entitle him to receive otherwise confidential news and to send comments and

20. Neumann, Behemoth; The Structure and Practice of National Socialism 1933-1944 (1944) has a compact review of Nazi methods of control. On the literature of theoretical and institutional comparisons, see the critical articles by Heimann in (1939) 6 Social Research 88 and (1946) 13 id. at 103.

21. Among many significant books are Mayo, The Human Problems of an Industrial Civilization (1933); Barnard, The Functions of the Executive (1945); Whitehead, Leadership in a Free Society (1936); Roethlisberger, Management and Morale (1941); Metcalf and Urwick (eds.), Dynamic Administration: The Collected Papers of Mary Parker Follett (1942); Leighton, The Governing of Men (1945); Appleby, Big Democracy (1945); Marx (ed.), Public Management in the New DeMOCRACY (1940); Urwick, The Elements of Administration (1944). 
recommendations through designated channels.) ${ }^{22}$ Enlightened leaders would also insist upon applying the principle of appreciation, the adjustment of respect and of income in ways that stimulate maximum production. A major feature would be efforts to wipe out inequities in the treatment of America's "second-class citizens," the Negroes, ${ }^{23}$ and certain other racial and religious groups. (In practice, the application of the foregoing principles of democratic action will be frustrated to the extent that unenlightened executives and unliquidated bias remain.) ${ }^{24}$

Since totalitarian institutions are already established in the Russian zone, there would be fewer changes than in the American way of life. There would, of course, be recurring waves of discontent with the sacrifices entailed by incessant preparation for war. Undoubtedly this dissatisfaction would express itself in the typical defense-reactions of human beings exposed to continual stress-in slowness, clumsiness, carelessness, and illness. ${ }^{25}$ If war is deferred from year to year, Russian executives will find it expedient to give more material rewards to the labor force, raising the production of consumers' goods to a point judged compatible with the optimum production of war goods.

It is not "inevitable" that the strain of living in the shadow of war will result in either side taking the offensive. War would be exceedingly dangerous to the ruling groups of both zones. The "first button" might wipe out the cities (and known vital points) of the enemy, but this would not spell victory since the military authorities of both powers would keep known vital spots of the other under constant surveillance, with machinery poised for instant retaliation. Even the most cynical leader - the more or less mythical homo politicus, the methodological twin of homo ceconomicus - would hesitate to run the risk, not only of losing his life, but of touching off a conflict in which both the USSR and the USA would largely destroy one another, leaving behind a power vacuum to be occupied by the Argentine, Iran, Mexico, and other surviving middle (or small) powers. "Instant war" would be much more likely to culminate in two Carthages, not one Rome (in pluripolarity, not unipolarity).

If actual warfare is deferred from one year to the next, the expecta-

22. No doubt the bureaucrat's "initialed" channel would be universalized while the open broadcast, newspaper and film would disappear.

23. The scale of such problems is shown in Myrdal, An American Dilemma (1944).

24. The pattern of American culture has been characterized in a preliminary way by Lynd, Knowledge for What? (1939) and Mead, And Keep Your Powder Dry (1942).

25. The basic personality dynamisms under conditions of boredom and stress: Gillesspie, Psychological Effects of War on Citizen and Soldier (1942); Farago (ed.), German Psychological Warfare (1941); Mira, Psychiatry in War (1943); Grinker and Spiegel, Men Under Stress (1945); Chisholm, The Second William Alanson White Memorial Lectures (1946). 
tion of imminent violence will gradually recede into the background, save for occasional scares (perhaps engineered by the ruling groups to maintain internal discipline). Should the ruling groups in both zones succeed in maintaining a comparatively low level of internal tension (obviating any threat of revolution), eventually they may feel secure enough to expand the thin trickle of contact between the "two worlds." As the area of contact and confidence gradually extends, a movement toward "one world" would gradually get under way. (Institutions like the United Nations, however anemic today, would be available to implement a new trend toward world organization.)

\section{C.2 Preventive War}

Consider now the possibility that the USA will embark upon "preventive" war during the period before Russia attains weapon parity. Up to the present the overwhelming sentiment of the American people is for peace and security. The American people have been a notable exception to cynical maxims about power and imperialism. Knowing that we possess a super-colossal weapon, we have not been transformed into a baying pack of world conquerors. On the contrary the scientists who produced the bomb, stricken of conscience, took the lead in demanding internal control of nuclear fission by civilian, not military, authority and in insisting upon external control by a worldwide agency. American revulsion against the possibility of making affirmative use of the bomb was strengthened by the usual post-war withdrawal of interest from public to private affairs. Soldiers eager to get home, mothers and wives determined to hurry the soldiers home, politicians zealous to appease the veterans and their dependents, businessmen impatient to get out of government (and out of government controls) and back into business, farmers restless at price regulation, workers annoyed at wage ceilings - all these elements conjointly contributed to the swing from sacrifices on behalf of the public interest to the pursuit of immediate private advantage. The dominant sentiment was "the right to a private life" (to quote a remarkable slogan that cropped up among the garrison-ridden youth of Germany during the War).

Strong as such factors were in the first year after V-day, they are of diminishing importance in relation to foreign policy. The march of events is fanning older sentiments into flame. Many American groups have been indoctrinated for years with anti-Russian bias, and although anti-Russian propaganda was in abeyance during the last years of the War, it has already reappeared with unabated vigor, taking advantage of the difficulties of an unconcluded peace.

By themselves the anti-Russian elements in America are much too weak to bring about a crisis. Other groups would need to join. If during the next two or three years of negotiation for bomb control the American people come to regard Russia as the leading obstruction in 
the path toward security, preventive action against Russia would not be out of the question.

Before such a war could be started, the public would need to be fully alerted to the terrors of atomic war. They would need to believe that our government had struggled in good faith to obtain an effective agency of bomb control, and that Russia obstinately blocks a righteous plan. They would need to believe that Russian obduracy signifies that Russians are stalling for time to get bombs of their own in preparation for a surprise war to dominate the world (or, at least, to maintain an "intolerable" state of perpetual crisis in which our security of mind and our free institutions will perish). War would then appear to be a struggle, not against Russia, but against the enslavers of the Russian peoples, and the would-be enslavers of the peoples of the globe. War would not only be against something; it would be for something"A War to Make the World Safe."

From a strategic standpoint such a war would be no "thirty-minute" campaign. Enemy territory would need to be occupied as a follow-up on the bombing of enemy targets. The military forces of America and the allies of America would occupy all Siberia and all European Russia. It would not be possible, however, to annihilate the enemy's army without doing irreparable damage to civilians in friendly countries since the Red Army, deprived of bases in Russia, can overrun cities in Western Europe which we would be loath to destroy.

At the end of active hostilities, the length of occupation would depend upon the policies to be put into effect. A relatively short period would suffice if our aim were to install machinery for the international control of nuclear energy. But during the war period, some American leaders would undoubtedly go beyond this limited objective and insist upon dismembering the USSR and restoring private capitalism (at least of international privately owned monopolies of mines, utilities and heavy industry). Such a program would be vehemently attacked by many other American leaders, who would assert that any attempt to disinter capitalism would transform the globe into a vast revolutionary-counter-revolutionary arena (in which American leads reaction). They would argue that any tendency to convert a "preventive" war into a "reactionary" crusade would boomerang, widening the split in American morale already stimulated by the war itself.

It is uncertain which trend of policy would win, but the champions of minimum intervention would undoubtedly be handicapped by the anti-communist, anti-Russian, anti-socialist ideology prevalent during the war, and by repressive measures put into effect by military and police authorities. Also, the conquest of Russia would not necessarily guarantee American security. There would be perpetual rumours of anti-American conspiracies and of new, deadly and compact secret weapons. Our authorities would not only search for signs of subversive 
activity throughout Russia; they would view every nation with suspicion, wondering whether Mexico City, Madrid, or Buenos Aires harbored conspirative cells and secret laboratories devising new tools of death. Our leaders would be tempted to wage another, and yet another, "preventive" war in order to enlarge the area policed from Washington.

The shock of the first "preventive" war (the one against Russia) would have opened great cleavages among the American people, where there are many persons for whom the Soviet Union is the beaconlight of humanity. The admirers of Russia are by no means exclusively recruited from racial and other "second class" citizens of the United States. In war genuine seditionists would shock the ruling elements of America into defensive repression, tending to transform the USA (and all dependent countries) into a garrison-prison state. Each successive war of "prevention" and each successive intimidation of a "doubtful" state would alienate a new group of Americans. Since the dissenters would be distributed widely throughout the nation, the ruling groups would generate inner tension and conflict.

Perhaps the leaders of "Imperial America" would be able to protect themselves from assassins and revolutionists by ruthlessly applying modern scientific and technical methods (although atomic bombs, for instance, would be too unwieldy for most internal use). The loyalty of every individual could be put under the unremitting surveillance of military and police intelligence. Everyone could be required to undergo a regular medical and psychological examination (quarterly or annually) which would include tests to determine the presence or absence of "dangerous thoughts." (Each person could be put under the influence of drugs and questioned.) ${ }^{26}$ Besides the application of scientific methods to enforce disclosure, other possibilities, long ago foreseen, may be adopted. Quite likely there are ways of incapacitating actual or suspected opponents, without depriving them of some usefulness in production. The technical problem would be to destroy the higher cortical centers, while retaining enough coordination to allow for the performance of repetitive operations. In this way permanent caste difference (permanent disparities in level of culture) could be established inside the garrison-prison state. ${ }^{27}$

There is the-possibility that at some point a revulsion against incessant violence will induce a spontaneous change of outlook among enough potent elements in society to reinstate the trend toward freedom (much as the "witch burning" craze came to an end in colonial New England). ${ }^{28}$ But it must be remembered that the absence of moral

26. Relevant to detection problems are recent advances in "narcoanalysis."

27. The present writer touched upon the possibilities of "Machiavelli, M.D." in World Politics and Personal Insecurity (1935) 282.

28. A case study: Taylor, The Witchcraft Delusion in Colonial Connecticut, 1647-1697 (1908). 
revulsion is one of the dominant characteristics of our day. This callousness does not come primarily from the love of cruelty but rather from terror arising from the expectation of unlimited violence. Millions of otherwise decent citizens have experienced the possibility that men can behave like savages, and concluded that savagery must be met by savagery. In the interest of self-preservation, and especially of the preservation of loved ones and cherished ideals, they have met rifle with tank, tank with plane, plane with rocket in a tragic attempt at self-protection that spirals into the attrition of humanity. (The American government killed more civilians with more dispatch at Hiroshima and Nagasaki than have ever been exterminated at one time in history. And there was no moral revulsion that threw out of office, and out of contact with decent human beings, every official who had any direct responsibility for the act.)

That Americans will encounter psychological difficulties if they undertake to run a world imperium is true; yet too much importance is not to be attached to our dubious record of occupation in Germany. ${ }^{29}$ A war for "World Government," for "World Security," for the "Control of Atomic Energy," could have a more potent ideological basis than an anti-Nazi campaign. For many Americans World War II was a struggle to stop a sadistic gang of thugs, but it was done without enthusiasm, without an overwhelming sense of mission. Somehow the whole business seemed a side issue in a world where there are major issues. It was as though we were building a modern house and found a slimy pterodactyl disputing the premises. Although everybody takes a hand in slaying the beast, the enterprise would nevertheless be felt as a diversion from the constructive task of finishing the house.

War to control atomic energy and to unite the world (under American leadership) would generate enough enthusiasm in many quarters to carry over into the post-war era. Although such enthusiasm would be offset by the admirers of Russia, it is clear that war against the leaders of a country that blocks the path to world security would not appear to be entirely atavistic. On the contrary it would seem to many elements in this country and abroad as the breaking down of barriers to the world community. It could be argued, and few would deny the point, that atomic energy ought to explode group privacy in the modern world. No one is safe when any group withdraws from full, neighborly contact with the rest of the world. Not only is the self-isolated group prey to delusions about what the rest of the world is doing and thinking, but the general anxiety level of everyone is increased through lack of reassuring contact. Hence it can be asserted that any government that cuts off its people from the free flow of information, travel and

29. The connection between the complex pattern called "capacity for administration" and empire was emphasized by Brooks Adams, The Theory of Social Revolutions (1913). 
knowledge is a menace to world safety and sanity. Thus the government of Russia could be stigmatized as the jailor of the Russian peoples, transforming them into delusion-ridden instruments of the mad ambition of a clique to rule the world. Hence the "War to Make the World $S a f e$ " is also a "War for World Neighborliness," a war for free speech, freedom of science, and freedom of travel. In such a perspective the conscience as well as the might of the American people, and of other peoples, could be directed against whatever regime tries to sabotage the effective control of fissionable material.

\section{C.3 International Control}

Let us now assume that an international agency is set up and is adequately staffed. Such an arrangement would substantially eliminate the probability of war in the visible future, and prepare the way for the further evolution of a worldwide civilization capable of sustaining an effective organization of the globe (without setting up a garrisonprison state).

Although international tension would not be abolished, threats to the common peace could be promptly nullified. If anti-Russian elements in America, or any other country, launch a hate campaign against the Soviet Union, alleging evasion, officials of the international control agency will be able to give the lie to ungrounded accusations. Not merely the friends of Russia, but all men of good will, will line up with control authorities and against inciters of hatred.

It is not to be overlooked that an effective agency of the kind postulated here is something new under the sun, representing an important modification in the prevailing taboos of both Russia and America. American business men are sensitive to the disclosure of trade secrets to competitors and rivals, yet it will be essential for them to concede the right of international authorities to investigate any plausible report of undisclosed supplies or illegal use of material. On their side, Russian leaders are particularly allergic to the disclosure of intimate facts to foreigners, and the permission to establish a well-equipped bomb control authority inside the USSR would be a drastic innovation.

We can be certain that the leaders of the USSR will have in mind the possibility that whatever authority is set up will learn that Russia is weak in fissionable material, in industrial "know how," and in facilities, and therefore that a war against Russia would stand an excellent chance of succeeding. If the USSR is really as weak as this, the rulers of the country will be strongly tempted to bluff and to sabotage the building of an adequate international authority. But this, as developed above, is to invite preventive war.

If the Russians agree to and cooperate in a powerful worldwide atomic authority, they will remove practically all danger of a preven- 
tive war against them. For this reason the Russian-hating elements outside Russia will do what they can to thwart an effective agreement. The Russian-haters will try in every way possible to cast suspicion upon the good faith of Russia, hoping to make the Soviet Union the scapegoat for protracted or stalled negotiations. The friends of Russia and, more importantly, the friends of American and world security as a whole, cannot be sure of nullifying this propaganda unless the Soviet government adopts the "propaganda of the deed" by giving emphatic assent to an atomic energy agreement and frank cooperation in putting final arrangements into effect. ${ }^{30}$

The general result of the foregoing analysis is that if war does not occur before Russia has attained weapon parity (and no agreement is made for international control), the trend will continue for some time toward more rigid bipolarity, accompanied by chronic threat of war. In the end a unipolar consensus may gradually arise between the independent spheres. There is, however, danger of "preventive" war designed to forestall Russian parity, a danger which can best be obviated by the friends of world security if they have the help of an unequivocal and confidence-inspiring Russian policy toward the international control of fissionable material. Such a control, once inaugurated, would greatly diminish both the likelihood of war and the rigidity of bipolar patterns of power and society.

\section{The Trend toward Scientific and Democratic Homogeneity}

Besides the trend toward bipolarity another conspicuous feature of world affairs is the trend toward a particular pattern of internal homogeneity throughout the globe.

A. As modern science and technology move towards universality, certain uniformities are imposed upon world attention, and attitudes are moulded in similar ways.

Long a monopoly of Western Europe modern science and technology are spreading throughout the globe, although at present inhibited by the elements that are finding expression through the bipolar pattern of power. Certain consequences follow inexorably from the appearance of the "machine" (to use a condensed way of referring to the modern

30. Public opinion polls provide important clues to American attitudes toward Russia. The most important finding is that during the years since national polls were put on a systematic basis, a relatively small percent of the population stays "pro" or "anti" during thick and thin. This shows how much importance must be attached to factors in the current environment of the community, rather than to crystallized predispositions. Polling data are regularly available in the Public Opinion Quarterly and in Bruner, Mandate from the People (1944); Cantril, Gauging Public Opinion (1944). On the dynamics of opinion, see Lazarsfeld, Berelson, and Gaudet, The People's Choice: How the Voter Makes Up His Mind in a Presidential Campaign (1944). 
techno-scientific complex). The machine confers a sense of mastery. Even those who at first are mastered do not fail to observe and presently to admire the impersonal strength and precision of mechanical, electrical, and other forms of energy applied to production. On the basis of direct experience, certain inferences sprout into belief and harden into faith, such as the speculation that if the brain of man can grasp and shape the bidden dynamics of Nature, man is capable of controling himself and his gadgets for the common good. This inference comes not from propaganda or pedagogy alone, or even principally; rather, it rises from indelible impressions left by association with man's handiwork. From glimpses of the possible develop demands that authority be induced or coerced to make whatever provision is necessary to share the fruits of knowledge with the "common man." However supine the traditional outlook of any culture, contact with the machine touches off a dynamic approach to life. ${ }^{31}$

B. The Universal demands include equal opportunity to acquire, exercise, and reward socially useful skill.

The first contact with the machine spelled frustration for millions of workers when complicated operations were subdivided into simple processes performed by contrivances ranged along an assembly line. Human operatives were constrained to adapt themselves to the metronome beat of machinery.

This shredding of life into compartmentalized boredom is not inherent in the application of mechanical, chemical and other forms of energy to production. The machine that brings frustration brings the possibility of escape into a larger life of self-expression. This is a matter of the hours spent at work and the degree of command over facilities in leisure time. Provided that the individual is able to emancipate himself from too many hours on the assembly line, and provided, further, that he commands a steady and substantial income, he can share the new freedom inaugurated by the unending novelties introduced by science and technology.

Outworn ways of thinking have kept the creative diversity of the machine from being recognized by many executives and analysts, although the dynamic impact of technology has set in motion tendencies to correct early abuses. ${ }^{32}$ The demand for education, full employment, shorter hours, better housing, proper medical care, abundant recreational facilities-all such demands give shape to the major social movements of modern history. Wherever the new knowledge has been

31. A mine of information is Sombart, Der proletarische Sozialismus, (1924).

32. Economic and literary historians of early capitalism in England and elsewhere have kept alive a grossly exaggerated set of social images related to the machine. Modern studies of the sociology and psychology of the worker are steadily dissolving the older notions. 
adapted to the reorganizing of production, the same chain of effect has been released-the same demand for education, for an income-producing job, and for a respected place in society. Brief reminders:

Skill Acquisition. Hand in hand with the expanding market has gone the spread of literacy, of systems of free public instruction, of compulsory school attendance, of prohibition of child labor, of advanced and technical schools covering every phase of human knowledge, appealing to adult as well as youth and child. ${ }^{33}$

Skill Exercise. The trend has been toward providing opportunities to make use of skill as well as to acquire it. The demand is exhibited in the watchword "Careers open to talent," in the name of which all manner of restrictions have been liquidated (against the employment of women, of racial and other minority groups). The struggle to iron out the business cyle and to provide emergency relief or employment are part of this trend. ${ }^{34}$ (In Socialist economies the "right to work" is already written into basic law.) ${ }^{35}$

Skill Reward (Respect). To be "occupied" is not enough; a "job" implies a respected place in society, a continuous flow of self-respect as part of the reward of exercising a socially accepted skill. "Leaf raking" is not a true job, nor is compulsory labor. The modern protest against mass unemployment comes from the circumstance that being thrown out of a job is more than losing money income; it means the loss of a respected place in society..$^{36}$ For many generations the "dignity of work" has been a major slogan of all fighters against contempt for toil, against "aristocratic" disdain of measuring personality by what one can $d o$, rather than by who one $i s$.

Skill Reward (Income). "Equal pay for equal work" is a protest against inequities in income that are rationalized in terms of sex, age, or minority status. The taxation of inheritance is one manifestation of the demand to reduce or eliminate all forms of "unearned" income-by gift, marriage, racketeering, gambling, monopoly, exploitation, discovery. ${ }^{37}$ (The demand for a "minimum wage" is chiefly a means of maintaining basic human dignityrespect-rather than of accomplishing other purposes. $)^{38}$

33. A guide to the abundant data is provided by the Encyc. Soc. Sciences (19301934) articles on the history of all forms of education.

34. See Millis and Montgomery, Labor's Risks and Social Insurance (1938).

35. Article 118 of the U.S.S.R. Constitution of 1936 declares that all citizens have the "right to work"; article 119 recognizes "the right to rest and leisure," and subsequent articles deal with related matters.

36. Articles on discrimination and upon racial and other social movements in the ENCYC. SoC. SCIENCES (1930-1934) are convenient guides.

37. A manual of American experience with side-glances at the general trend is Groves, Financing Government (1939).

38. Note John A. Ryan's influential little classic, A Living WAGE (1906), expressing the progressive Catholic trend. 


\section{Another demand is for a share in decision making, in the control of skill.}

The rising self-consciousness of modern man has intensified conflicts centering around the making of decisions (in government, business, etc.). Historically, certain forms of despotism were swept away, and to a certain extent democracy in government has been accompanied by freedom in the market place. ${ }^{39}$ Where markets are private monopolies, self-control is reduced or lost. In modern times the demand to share in the control of skill has so often been sacrificed to some other skill demand, like job security, that the trend toward skill control is less conclusive than toward equal opportunity to acquire, exercise and receive the rewards of skill.

D. Homogeneous institutions are appearing throughout the world, bringing a new equilibrium of collectivizing-individualizing tendencies.

As A. V. Dicey wrote many years ago, ${ }^{40}$ and as many others have written before and since, the trend of civilization may be said to be from "individualism" to "collectivism," a tendency most dramatically expressed in Russia. It is somewhat misleading to speak of the trend in doctrinal ("ism") terms since doctrines do not invariably foster the tendencies in the name of which they are formulated. "Individualism" for instance can be used to thwart the individuality of the worker for the benefit of the boss. We need to be on guard against assuming that the actual institutions of high capitalism did in fact provide the greatest net encouragement to individualizing tendencies that can be realized in human society. Many devices have already been invented which may, under appropriate conditions, improve on the period of capitalistic dominance. The new sciences of human relations are sufficiently advanced to stimulate the discovery of many new ways of sustaining creative tension between individualizing and collectivizing tendencies. ${ }^{41}$ Whether these potentialities can be realized depends,

39. Where markets are genuinely competitive, skill control is relatively automatic, since executive, technician and laborer can share in the choices that affect them by changing employers.

40. Lectures on the Relation between Law and Public Opinion in England During the Nineteenth Century (1905). On actual developments, see Lawley, The Growth of Collective Economy (1938).

41. Contrast with the sterile dogmatism of Mises, Omnipotent Government (1944) and Hayek, The Road to Serfoom (1944), the problem-seeing, inventive approach of Merriam, Systematic Politics (1945); Ruml, Tomorrow's Business (1945); Bunbury, Governmental Planning Machinery (1938); Mannheim, Man and Society in an Age of Reconstruction (1940); Lilienthal, TVA; Democracy on the March (1944); Golden and Ruttenberg, The Dynamics of Industrial Democracy (1942); The Twentieth Century Fund, How Collective Bargaining Works (1942); Gordon, The Public Corporation in Great Britain (1938); Robson (ed.), Public Enterprise (1937). 
of course, upon the total context, and especially upon the level of insecurity in world politics.

E. Homogeneity of social structure does not necessarily carry with it either uniformity of doctrine or a single state.

The present trend toward homogeneous institutions among the principal states and societies of the world is no new phenomenon. All the major peoples of Western Europe passed from "feudalism" to "capitalism" without adopting a standard doctrine or setting up an inclusive state.

Indeed, one seemingly paradoxical detail of the process by which modern capitalism triumphed was the appearance of an outspoken revolutionary movement demanding uniformity of doctrine and world unity, by force if necessary. The French Revolution was one of the many avenues by which the general trend against "feudalism" and "autocracy" was instrumented.

In general, we may say that a distinction is necessary between the world revolutionary pattern of an epoch and the pattern of the center, where new doctrines and élites emerge to power. The original pattern of the center is by no means to be confused with the general pattern of the epoch. The original pattern is not totally diffused throughout the political arena, and undergoes restrictive modifications from within and without, in the course of which the "common denominator" emerges, which is characteristic of the epoch as a whole.

In our period the center of world revolutionary activity is unmistakably Russia. But, as usual, the pattern of the epoch is not entirely clear to the contemporaries of the event. One conclusion, however, is probable. It is unlikely that the doctrine of the Russian Revolution is the doctrine of the epoch, or that the pattern of the epoch will coincide with the original pattern of the Russian Revolution. Already it is apparent that the doctrines and methods of the early period have been modified at home and abroad. But the forecast remains: the world is moving toward homogeneous social structure, regardless of whether political unipolarity is early or late. ${ }^{42}$

42. On the meaning of current developments note such interpretations as the following: Lenin, Imperialism, the Highest Stage of Capitalism (1933); Trotsky, The Permanent Revolution (1931) and The Revolution Betrayed (1937); Nomad, Rebels and Renegades (1932); Benda, The Great Betrayal (Aldington's trans. 1928); Berdiaev, The End of Our Time (1933); Borkenau, Socialism, National or International (1942); Burnham, The Managerial Revolution (1941); Dennis, The Dynamics of War and Revolution (1940); Friedmann, World Revolution and the Future of the West (1942); Lasswell and Blumenstock, World Revolutionary Propaganda (1939). On structural changes in modern élites, see Sorokin, Social Mobility (1927); Michels, Umschichtungen in deN herrschenden Klassen nach dem Kriege (1934); Ross, Parliamentary Representation (1944); Holcombe, The Middle Classes in American Politics (1940); Gurvitch, Social Structure of Pre-War France (1943) 48 Am. J. Soc. 535; 
F. In spite of doctrinal differences and political independence, unity of moral attitude is possible.

Although the world is divided by sharp doctrinal disagreements, certain basic moral attitudes are held in common. Ever since the defeat of Nazi racialism, the ideology of every major power proclaims the dignity and worth of human personality. The significance of the trends toward a commonwealth of skill is that skill adjustments are indispensable means to the fulfilment of human personality, especially in an epoch of science and technology. Marxist and liberal traditions share one central theme, the aspiration toward a "free man's commonwealth" or a "free society." Both Marxism and liberalism are antiaristocratic, anti-caste. They are individualistic in the sense that they insist that all men shall be respected for their common humanity.

A factor in meliorating the present crisis in human affairs can be wider recognition of the common moral attitude that overrides detailed disputes about doctrine and about whether specific institutional devices do, in fact, implement the moral goal. It is too much to expect that this factor, or any simple combination of factors, will mitigate the present conflict and rescue humanity from suicide. But a common goal is a guide to men of good will everywhere and a practicable basis of appeal for common action before it is too late. ${ }^{43}$

\section{CONCLUSION}

Our review of world trends toward bipolarity and toward scientific and democratic homogeneity have shown how often they facilitate and how often they interfere with one another. A new level of technoscientific culture must be widely shared before its full benefits can be attained. But the trend toward homogeneity arouses and intensifies restrictive factors which operate to limit, halt or reverse the even spread of such innovations as the modern techno-scientific pattern to many sub-centers throughout the world. These defensive adaptations have resulted not in creating universality of culture, but in concentrating developments in certain zones.

The aggregate impact of political considerations and conditions has been to limit the trend toward homogeneity and to drive it toward

Timasheff, Vertical Social Mobility in Communist Society (1944) 50 Am. J. Soc. 9; BIENstock, Schwarz, and Yugow, Management in Russian Industry and Agriculture (1944); Gerth, The Nazi Party: Its Leadership and Composition (1940) 45 Am. J. Soc. 517.

43. The possibility of agreement on moral objectives, while doctrinal postulates remain intact, is exemplified in the Conference on Science, Philosophy and Religion in Their Relation to the Democratic Way of Life. See, in particular, Fourth Symposium, Approaches To World PeAce (ed. by Bryson, Finkelstein, and MacIver) (1944). Small loyalties are suffering attrition in the modern world. See especially Friedmann, The Crisis of THE National State (1943); Carr, Conditions of Peace (1942). On the ultimate need of a world organization see West, Conscience AND Society (1945). 
strengthening two polar centers. The overwhelming productive capacity of the new techno-scientific pattern has heightened cultural disparity and fostered the tendency toward few rather than many states. First a few great powers, later three super-powers, and more recently two giant powers become the decisive poles affecting the world balancing process. Today we are witnessing a struggle between the elements expressing themselves through the bipolar pattern to protect the bipolar pattern against the unipolar potentials of the new energy developments.

An attempt to impose world unipolarity by conquest at the present time would tend to halt the present trend toward homogeneity and to stereotype existing disparities and contradictions into relatively permanent castes. The élite that would saddle itself upon the world by conquest would face recurring waves of sedition fed by the disparities and contradictions of present day humanity. In reply, the world élite would in all probability seek to defend itself by instituting a garrisonprison state, in which control would be in the hands of a relatively few specialists on violence (the world police). In such a caste society equal opportunity for the acquisition, exercise, and rewarding of socially useful skill would go by the board.

If weapon parity is attained between the two great polar centers and no effective world control is instituted, the first effect will be to complete the creation of two non-penetrating worlds, thus rigidifying the present tentative bipolarity of power and culture. Chronic and intense fear of "push-button war" would contribute to the appearance of two garrison states, and fear of sedition would operate them like prison states. Should war be deferred from year to year, as the leaders recognize the danger of mutilating one another for the benefit of others, there would be a gradual revival of contact between the two garrison-prisons. Through the enlarging apertures would come revived exchange of news, knowledge, persons, products and agreements, thus reinstating the trend toward cultural homogeneity and political unification.

If the destructive consequences of "preventive" war or of continuing. acute fear of war are to be avoided, arrangements must be promptly completed for the control of our most devastating weapons. Such an arrangement would not signify the coming of the world state or the completion of a genuine world society. It would, however, be a decisive step toward the eventual integration of humanity, toward the triumph rather than the annihilation or the degradation of man. 